\title{
DINÁMICA FERMENTATIVA Y FRACCIONAMIENTO PROTEÍCO DURANTE EL ENSILAJE DE MANÍ FORRAJERO (CIAT 17434) ${ }^{1}$
}

\author{
Rodolfo WingChing-Jones ${ }^{2}$, Augusto Rojas-Bourrillón ${ }^{2}$
}

\begin{abstract}
RESUMEN
Dinámica fermentativa y fraccionamiento proteico durante el ensilaje de maní forrajero (CIAT 17434). Se analizó el comportamiento fermentativo del ensilaje de maní forrajero (CIAT 17434) cada 10 días durante un periodo de 60 días, cosechado en San Carlos, Costa Rica, durante el mes de octubre del año 2001. El material a ensilar se cosechó a 12 semanas, se picó y se le adicionó $6 \%$ de melaza con relación al peso fresco de la muestra. El contenido de materia seca (MS), proteína cruda (PC), fibra detergente neutro (FDN), fibra detergente ácida (FDA) y el valor de $\mathrm{pH}$ del ensilaje sufren una disminución durante los 60 días de fermentación, de 25,57, $5,10,18,00,10,00$ y $5,10 \%$, respectivamente. En cambio, el contenido de nitrógeno amoniacal, la capacidad buffer, la concentración de ácido láctico y acético aumentaron, con un valor porcentual de $112 \%$ y valores promedio de 98,69 meq de $\mathrm{NaOH} / 100$ g, 3,67 \% MS y 6,16\% MS, respectivamente. Con relación al fraccionamiento de la proteína el material a ensilar presentó un tercio del contenido proteíco soluble, un tercio insoluble aprovechable y un tercio indigerible, mientras que por efecto del proceso fermentativo el contenido de PC soluble se mantuvo (33\%), la PC-insoluble aprovechable aumentó a $51 \%$ y la de PC indigerible se redujo a $16 \%$. El ensilaje de maní forrajero se puede emplear como alimento para animales de alto potencial productivo (leche y carne) a partir de los diez días post-fermentación, ya que se estabiliza el sistema y que presenta una gran proporción de proteína de sobrepaso.
\end{abstract}

Palabras clave: Ensilaje, leguminosa, Arachis pintoi, dinámica fermentativa, fraccionamiento de la proteína.

\begin{abstract}
Fermentative dynamic and crude protein fractions of perennial forage peanut silage (CIAT 17434). Fermentative dynamics of perennial peanut silage (CIAT 17434) was analyzed every 10 days during a 60 day fermentation period, harvested on October 2001 in San Carlos city. Plant material was harvested at 12 weeks and stored in plastic bag silos of $1 \mathrm{~kg}$ of capacity. Molasses was added at $6 \%$ as fed basis. Dry matter content (DM), crude protein $(\mathrm{CP})$, neutral detergent fiber (NDF), acid detergent fiber ( $\mathrm{ADF}$ ) and $\mathrm{pH}$ value of the silage diminished in 60 days of fermentative period, in 25.57, 5.10, 18.00, 10.00 and $5.10 \%$, respectively. In other hand, $\mathrm{N}$-ammonia content (N-N total), buffering capacity analysis, lactic acid concentration and acetic acid concentration increased, in $112 \%$ and average value of $98.69 \mathrm{meq} \mathrm{NaOH} / 100 \mathrm{~g}$, $3.67 \% \mathrm{DM}$ and $6.16 \% \mathrm{DM}$, respectively. Initially, on day zero of fermentation, the material presented a third of soluble protein, one third as bypass protein and the remaining as unavailable protein, whereas by effect of the fermentative process the content of soluble protein remained similar $(33.05 \%)$, the bypass protein increased to $51.38 \%$ and unavailable protein reduced to $16.04 \%$. Perennial peanut silage can be used as feed for animals of high productive potential (milk and meat) starting ten days post-fermentation, since the system becomes stabilized and it presents a great proportion of bypass protein.
\end{abstract}

Key words: Silage, Arachis pintoi, legume, fermentative dynamic, crude protein fractions.

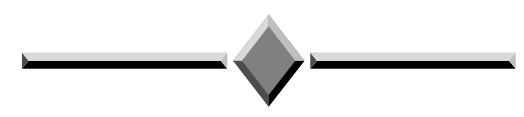

\section{INTRODUCCIÓN}

Durante los últimos años se ha estado estimulando el empleo del maní forrajero (Arachis pintoi) como componente en las dietas del ganado lechero (Argel y Villareal 1998). Las experiencias indican que puede ser suministrado mediante bancos de proteínas, como única fuente forrajera de pastoreo y como forraje de

\footnotetext{
1 Recibido: 19 de junio, 2006. Aceptado: 6 de marzo, 2007. Proyecto de Investigación 739-AO-056, Universidad de Costa Rica.

2 Escuela de Zootecnia. Centro de Investigación en Nutrición Animal. Universidad de Costa Rica Correo electrónico: rwingchi@cariari.ucr.ac.cr; augustor@cariari.ucr.ac.cr
} 
corte. Al valorar su rendimiento (24-26 t MS/ha/año) y calidad nutricional (Argel y Villareal 1998) se considera necesario evaluar también sistemas de conservación, como el ensilaje, que permitan incrementar su utilización en la alimentación del ganado.

No obstante, debido a la escasa disponibilidad de información al respecto, se reconoce la necesidad de indagar más sobre la fermentación que sufre esta planta durante el proceso de ensilaje. El proceso que conlleva la elaboración de un ensilaje se basa en crear un ambiente anaeróbico, y la formación natural del ácido láctico que disminuye el $\mathrm{pH}$ entre 3,5 y 4,0. Se ha encontrado que durante el proceso de fermentación del ensilaje existen tres fases y dos tipos de fermentación (Pezo 1981), lo que varía de acuerdo al tipo de forraje ensilado y a la práctica de manejo.

Dentro de las fases descritas se encuentra: la aeróbica, la cual se denomina también fase de respiración, está comprendida entre el momento que se realiza el corte del material a ensilar y el momento que se logra compactar el material, y la anaeróbica, comprendida por la fase de fermentación, realizada por bacterias anaeróbicas y la fase de estabilización que se alcanza cuando la producción de ácido láctico provoca la inhibición del crecimiento bacterial (Pezo 1981).

Entre los tipos de fermentación se encuentra la homofermentativa, la cual se considera ideal, provoca la conversión directa de la glucosa a ácido láctico por bacterias del género Lactobacillius sp. En la fermentación heterofermentativa, se transforma la glucosa en ácido láctico, etanol y dióxido de carbono, y en la costridial (Clostridium sp.) transforma el ácido láctico a ácido butírico, dióxido de carbono e hidrógeno provocando valores altos de $\mathrm{pH}$ y el deterioro del material asociado a la producción de compuestos tóxicos para el animal (McDonald 1981). En el ensilaje de maní se desconocen las características químicas que gobiernan este proceso como lo son: el pH, la formación de ácidos grasos, las concentraciones finales de estos y el contenido de nitrógeno amoniacal. Por tal motivo, el objetivo de este trabajo fue caracterizar la fermentación del ensilaje de maní forrajero y determinar las fracciones de la proteína cruda durante el proceso.

\section{MATERIALES Y MÉTODOS}

\section{Forraje}

El material utilizado fue cosechado en Santa Clara de San Carlos, en la finca de la sede regional del Instituto Tecnológico de Costa Rica, en el mes de octubre del año 2001, se trabajó con el ecotipo CIAT 17434, cortado a las 12 semanas de rebrote y con $6 \%$ de melaza adicionada con relación al peso fresco de la muestra (28,57\% de melaza en base seca).

\section{Microsilos y tratamientos}

La descripción del manejo del material y la elaboración de los silos, se describe en WingChing-Jones y Rojas-Bourrillón (2005). Básicamente se trabajó con 10 repeticiones en cada ciclo fermentativo de 10 días durante un lapso de 60 días, para un total de seis ciclos fermentativos. El material picado y con previa adición de la melaza se depositó muestras de $1 \mathrm{~kg}$, en bolsas de plástico de $0,063 \mathrm{~mm}$ de espesor, a las cuales se les extrajo el aire mediante una bomba de vacío e inmediatamente se sellaron. Las bolsas se colocaron en posición horizontal en una estantería bajo condiciones ambientales de temperatura $\left(18-26^{\circ} \mathrm{C}\right)$ y humedad relativa (80-95\%) durante 60 días.

\section{Análisis químico}

Tanto en las muestras tomadas al día cero de iniciada la fermentación como en las tomadas durante cada ciclo de fermentación, se analizó el contenido de materia seca (MS) en estufa a $60{ }^{\circ} \mathrm{C}$ durante $48 \mathrm{~h}$ y proteína cruda (PC) (AOAC 1990); fibra detergente neutro (FDN) y fibra detergente ácida (FDA) (Van Soest y Robertson 1985), mientras que, el contenido de nitrógeno amoniacal (\% del nitrógeno total) (AOAC 1990) se determinó en las muestras después de cada ciclo fermentativo.

El pH se midió según la metodología descrita por Rojas (1985) en donde se tomaron $20 \mathrm{~g}$ por duplicado de cada muestra y se mezclaron con $80 \mathrm{ml}$ de agua 
destilada, se agitaron durante cuatro horas, se filtraron y al líquido obtenido se le midió el pH con un potenciómetro de vidrio.

La capacidad buffer del material después de cada ciclo se determinó mediante la metodología indicada por McDonald y Henderson (1962), y para la determinación de los ácidos grasos volátiles se siguió la metodología descrita por Tobía (2004), por medio de cromatografía de gases.

\section{Fraccionamiento de la proteína}

Para el fraccionamiento de la proteína, se utilizó la metodología propuesta por Licitra et al. (1996) en el cual se separan las fracciones proteicas $\left(A, B_{1}, B_{2}\right.$, $\mathrm{B}_{3}$ y C) por medio de su capacidad de solubilización en diferentes medios acuosos.

\section{Análisis estadístico}

La información fue analizada utilizando procedimientos de regresión con el fin de obtener curvas de mejor ajuste a través del tiempo de ensilaje (SAS 1985).

\section{RESULTADOS Y DISCUSIÓN}

\section{Materia seca (MS)}

El contenido de materia seca del ensilaje experimentó una reducción del 24,52 \% durante los primeros 10 días del proceso fermentativo, a partir del cual se estabilizó con un valor promedio de 15,83 $\pm 0,23 \%$ durante los 50 días restantes (Cuadro 1). Esto se debe a que durante la primera etapa del ensilaje, el material continúa respirando (Moore y Peterson 1995).

McDonald et al. (1991) informa que los estomas de las planta permanecen abiertos entre $0,5 \mathrm{y}$ dos horas después de la corta, lo cual genera pérdidas por dióxido de carbono $\left(\mathrm{CO}_{2}\right)$, calor y agua (Moore y Peterson 1995). La estabilización del contenido de materia seca se debe a la presencia de un adecuado sustrato (carbohidratos solubles) para el crecimiento de las bacterias lácticas, que propicia el descenso del pH y la formación de ácido láctico. Comparando el contenido de MS del ensilado de maní forrajero con los ensilados de maíz y pasto elefante informados por Dormond et al. (2000), se observa que son más bajos (24,9\% y $18,2 \%$ de $\mathrm{MS}$, respectivamente).

\section{Proteína cruda (PC)}

El ensilado de maní forrajero promedió 17,98 $\pm 0,53 \%$ de PC con cambios mínimos en su contenido durante el proceso (Cuadro 1). Este contenido proteico es superior al informado por Dormond et al. (2000) para el ensilaje de maíz (6,9 \% PC MS) y de pasto elefante (11\% PC MS), lo que sugiere que este valor puede mejorar el balance energía/proteína a nivel ruminal a un bajo costo. Los valores cuantificados en esta investigación son $1,17 \%$ menores $(19,15 \%$ contra $17,98 \%$ ) a los encontrados por Tobía (2004) para el ensilaje de soya.

En el Cuadro 1 se describe el comportamiento que presentó el contenido de PC en el ensilaje durante el proceso fermentativo con una tendencia a la reducción del contenido proteíco, debido a la transformación de esta fracción hacia componentes nitrogenados más solubles (N-amoniacal). Givens y Rulquin (2004) informan de reducciones de $42,23 \%$ en el contenido de N-proteico en ensilajes de trébol rojo, en esta investigación la reducción fue de $81,44 \%$.

\section{Fraccionamiento proteico}

Los valores describen la solubilidad que presentan las diferentes fracciones que componen la proteína en soluciones ácidas y/o básicas. La solubilidad que presenta la fracción A es muy alta, conformada por nitritos, nitratos, aminoácido y pépticos, la $\mathrm{B}_{1}$ es de rápida solubilidad (globulinas y albúminas), $\mathrm{B}_{2}$ de solubilidad variable (albúminas y glutelinas) y la $\mathrm{B}_{3}$ se considera de variable a lenta (prolaminas, extensinas, proteínas desnaturalizadas). La fracción $\mathrm{C}$ es considerada de poco provecho para el animal por estar conformadas por productos resultantes de reacciones de Mailard y al nitrógeno ligado a la lignina (Chalupa y Sniffen 1996). 
Cuadro 1. Dinámica de la composición nutricional y parámetros fermentativos del ensilaje de maní forrajero durante 60 días de fermentación. Alajuela, Costa Rica, 2001.

\begin{tabular}{|c|c|c|c|c|c|c|c|c|c|c|c|}
\hline \multirow{2}{*}{ Variable } & \multirow[t]{2}{*}{ Unidades } & \multicolumn{7}{|c|}{ Periodo de fermentación (días) } & \multirow{2}{*}{ Efecto } & \multirow[t]{2}{*}{ Ecuación de predicción } & \multirow[t]{2}{*}{$\mathbf{R}^{2}$} \\
\hline & & $\mathbf{0}$ & 10 & 20 & 30 & 40 & $\mathbf{5 0}$ & 60 & & & \\
\hline Materia seca (MS) & $\%$ & 21,00 & 15,93 & 15,95 & 15,48 & 16,05 & 16,02 & 15,63 & Polinomial & $0,0031 x^{2}-0,2424 x+19,855$ & 0,716 \\
\hline Proteína cruda (PC) & $\% \mathrm{MS}$ & 18,44 & 18,07 & 17,90 & 17,94 & 17,49 & 17,78 & 17,50 & Lineal & $-0,0136 \mathrm{X}+18,288$ & 0,788 \\
\hline $\begin{array}{l}\text { Nitrógeno } \\
\text { amoniacal }\end{array}$ & $\begin{array}{c}\mathrm{N} \text { amoniacal } \\
\text { /N-total }\end{array}$ & 5,83 & 9,88 & 10,63 & 11,21 & 12,07 & 13,03 & 12,37 & Lineal & $0,0977 X+7,7847$ & 0,769 \\
\hline $\mathrm{pH}$ & - & 5,00 & 3,72 & 3,71 & 3,74 & 3,73 & 3,71 & 3,64 & Logarítmica & 3,7571- 0,0137x LN días & 0,991 \\
\hline Capacidad buffer & $\begin{array}{l}\text { meq } \mathrm{NaOH} \\
/ 100 \mathrm{~g} \mathrm{MS}\end{array}$ & 0,00 & 104,7 & 107,6 & 101,5 & 91,81 & 91,61 & 94,95 & Polinomial & $0,0046 x^{2}-0,6251 x+1$ & 0,721 \\
\hline $\begin{array}{l}\text { Fibra detergente } \\
\text { neutro (FDN) }\end{array}$ & $\% \mathrm{MS}$ & 55,04 & 48,82 & 46,84 & 49,57 & 47,55 & 42,41 & 45,13 & Polinomial & $0,0023 x^{2}-0,2872 x+53,54$ & 0,724 \\
\hline $\begin{array}{l}\text { Fibra detergente } \\
\text { ácida (FDA) }\end{array}$ & $\% \mathrm{MS}$ & 41,17 & 32,04 & 31,16 & 34,74 & 34,42 & 32,74 & 36,96 & Polinomial & $0,0065 x^{2}-0,421 x+38,87$ & 0,542 \\
\hline Ácido láctico & $\% \mathrm{MS}$ & 0,00 & 3,65 & 3,68 & 3,65 & 3,70 & 3,68 & 3,67 & Polinomial & $-0,0022 x^{2}+0,171 x+0,864$ & 0,728 \\
\hline Ácido acético & $\% \mathrm{MS}$ & 0,00 & 1,20 & 1,18 & 1,14 & 1,16 & 1,15 & 1,13 & Polinomial & $-0,0007 x^{2}+0,054 x+0,692$ & 0,692 \\
\hline
\end{tabular}

En el Cuadro 2 se describe el comportamiento de la fracción soluble, insoluble aprovechable e indigestible de la proteína presente en el ensilado de maní forrajero.

En relación al Cuadro 2, el maní forrajero sin ensilar a las 12 semanas de edad y con 6\% de melaza presentó un tercio de su contenido proteico con características de rápida asimilación, un tercio con características insolubles pero aprovechables y un tercio que el animal no logra aprovechar. Esta distribución es diferente a la encontrada para alfalfa sin ensilar de $40,5 \%$ para la fracción $\mathrm{A}+\mathrm{B}_{1} ; 54,6 \%$ para $\mathrm{B}_{2}+\mathrm{B}_{3}$ y $4,8 \%$ para fracción $\mathrm{C}$ (Elizalde et al. 1999), con incrementos en la fracción $\mathrm{C}$ al aumentar la madurez del forraje (Alzueta et al. 2001) Concordando con Brown y Pitman (1991) quienes informan de rangos obtenidos de proteína degradable, insoluble aprovechable e indigerible de $27,9 \%$ a $32,4 \%$, de $64,0 \%$ a $68,1 \%$ y de $3,6 \%$ a $4,0 \%$, respectivamente, para las leguminosas Aeschynomene americana e Indigofera hirsuta. Villarreal et al. (2005) en un ensayo previo, determinaron un contenido de $35,9 \%, 34,9 \%$ y $37 \%$ de proteína insoluble aprovechable para las variedades CIAT-17434, CIAT-17844 y CIAT-17448, respectivamente. Estos valores concuerdan con los resultados de esta investigación en el material antes de ensilar. Los valores de la fracción C determinados podrían estar aso-

Cuadro 2. Valor de las fracciones solubles, insoluble aprovechable e indigerible del ensilaje de maní forrajero durante el periodo fermentativo. Alajuela, Costa Rica, 2001.

\begin{tabular}{lcccccccc}
\hline \multirow{2}{*}{ Fracción } & \multicolumn{6}{c}{ Fracción proteica como \% de la proteína total durante el periodo de fermentación (días) } & \multirow{2}{*}{ Promedio* } \\
\cline { 2 - 6 } & $\mathbf{0}$ & $\mathbf{1 0}$ & $\mathbf{2 0}$ & $\mathbf{3 0}$ & $\mathbf{4 0}$ & $\mathbf{5 0}$ & $\mathbf{6 0}$ & \\
\hline $\mathrm{A}+\mathrm{B}_{1}$ & 32,12 & 31,37 & 34,57 & 29,80 & 37,15 & 35,82 & 29,57 & 33,05 \\
$\mathrm{~B}_{2}+\mathrm{B}_{3}$ & 37,30 & 52,29 & 49,90 & 54,36 & 48,70 & 49,74 & 53,32 & 51,38 \\
$\mathrm{C}$ & 30,58 & 14,56 & 13,76 & 13,84 & 12,23 & 12,72 & 14,58 & 16,04 \\
\hline
\end{tabular}

\footnotetext{
* Toma en consideración los valores durante el proceso de fermentación
} 
ciados a la edad de corte del maní en este trabajo, debido a que se afecta la relación hoja:tallo del material.

Durante el proceso fermentativo, la distribución de las fracciones proteicas se modifica, se mantiene el tercio soluble, pero se reduce a la mitad la cantidad de proteína indigerible, lo que aumenta el aporte del material con características insolubles aprovechables. Este comportamiento no es común debido a que se espera un aumento en la fracción $\mathrm{C}$ causado por el proceso del ensilaje (Chalupa y Sniffen 1996).

Con respecto a la distribución de las fracciones en relación al valor de proteína en el ensilaje de maní forrajero, la fracción A, promedió un valor de 5,80 \pm $0,61 \%$ de PC; las fracciones $\mathrm{B}_{1}, \mathrm{~B}_{2}$ y $\mathrm{B}_{3}$ de $0,14 \pm 0,02$ $\% ; 3,37 \pm 0,53 \%$ y $5,86 \pm 0,55 \%$ respectivamente, $\mathrm{y}$ $2,80 \pm 0,20 \%$ para la proteína indigerible por el animal. Los valores de proteína indigerible se encuentran dentro del rango normal, propuesto por Van Soest (1994) para los alimentos animales, de 3\% a $15 \%$ de N-ligado en fibra detergente ácida (N-FDA) y dentro del rango determinado por Mahanna (1997) de $12 \%$ a $15 \%$ de N-FDA para ensilajes que no presentaron daño térmico en su contenido de proteína.

\section{Nitrógeno amoniacal ( $\mathrm{N}-\mathrm{N}$ total)}

En los primeros 10 días el contenido de nitrógeno amoniacal se incrementó en 69,48 \% del contenido inicial (Cuadro 1), producto del proceso de proteólisis que ocurre durante la fase de respiración del ensilaje, lo cual fue asociado con un aumento en la fracción A de la proteína. Después de esta primera etapa, los incrementos porcentuales del contenido de N-amoniacal se vieron reducidos, en el periodo de los 10 a los 30 días, el aumento fue de 13,49\%; de los 30 a los 40 días de 7,64 \% y en el último tercio de 2,49\%; para un incremento total de $112,21 \%$ del contenido inicial de $\mathrm{N}$ amoniacal (Cuadro 1). Estas disminuciones en el contenido de $\mathrm{N}$-amoniacal se deben a que el proceso fermentativo se va estabilizando y se reducen las pérdidas de proteína durante el proceso. Según Rojas (1999) los ensilajes con concentraciones de nitrógeno amoniacal, con respecto al total de nitrógeno, entre 5 $\%$ y $8 \%$, se califican como excelentes.
Ensilajes de mala calidad se asocian con concentraciones mayores al $15 \%$, y como aceptables, las concentraciones menores al $11 \%$ (Moreno 1977). En este estudio, en promedio, el ensilaje de maní forrajero presenta 10,9 $\pm 0,02 \% \mathrm{~N}$-amoniacal del $\mathrm{N}$-Total, valor considerado como aceptable, resultado de un proceso que optimiza la conservación de la proteína durante el proceso.

\section{Pared celular}

\section{Fibra Detergente Neutro (FDN)}

El contenido promedio de FDN en el ensilado fue de 46,72 $\pm 2,62 \%$ en base seca (Cuadro 1), este valor es, en promedio, $22 \%$ inferior al presentado por los ensilajes de maíz (Dormond et al. 2000), lo cual favorecería el consumo del ensilado de maní forrajero por parte de los animales.

La concentración de FDN sufrió una reducción correspondiente al 11,27 \% del contenido inicial durante los primeros 10 días del proceso. Aunque en esta investigación no se cuantificaron los cambios en el contenido de celulosa y hemicelulosa, en la literatura esta documentado las reducciones que sufren estas fracciones, por ejemplo, Morrison (1979) informa de pérdidas en el contenido de celulosa y hemicelulosa resultado de la acción microbial en los ensilados, en cambio, Moore y Peterson (1995) describen un proceso de hidrólisis de los componentes de la pared celular y proteolisis por bacterias aeróbicas en las primeras horas de elaborado el ensilaje debido a que la planta sigue respirando. McDonald et al. (1991) sugiere que los productos de esta hidrólisis (celulosa, hemicelulosa y pectina) son utilizados por las bacterias como fuentes de azúcar, en los primeros días de la fermentación.

\section{Fibra Detergente Ácida (FDA)}

En el Cuadro 1 se observa que la FDA experimentó una disminución del 22,33\% durante los primeros 10 días, y en promedio 33,68 $\pm 2,11 \%$ FDA durante los 50 días restantes del proceso. Este bajo nivel de FDA favorece el uso del material anteriormente mencionado en dietas de animales de alta producción, que requieren forrajes de un alto aprovechamiento. 
En este trabajo no se cuantificaron los cambios que sufren las fracciones que conforman la FDA, pero en la literatura están documentadas las reducciones que sufren estos componentes, Singh et al. (1996) informan de reducciones en el contenido de lignina, para la leguminosa alfalfa (Medicago sativa), de 8,25 $\%$ en un periodo de fermentación de 35 días.

\section{pH y capacidad de amortiguamiento}

Durante los primeros 10 días, el pH se redujo en una cuarta parte, producto del proceso bacterial que sufre el material (Cuadro 1). Después de esta primera etapa fermentativa el material promedió un valor de $\mathrm{pH}$ de 3,71 \pm 0,04. Comportamiento similar es informado por Aguilera (1975), en ensilados de pasto Elefante presentando una rápida reducción del valor de $\mathrm{pH}$ a los 10 días de fermentación $(7,2$ a 3,8) con una relativa estabilidad a los 20 y 30 días del proceso, esta reducción, antes de los 10 días del proceso, propició que el contenido proteico del material se conservara, y que la producción de $\mathrm{N}$-amoniacal no alcanzara valores superiores a $15 \%$.

Hristov y Sandev (1998) informan valores de $\mathrm{pH}$ para el ensilado de alfalfa (10\% de floración) de 5,2, y McDonald (1981) para la leguminosa lucerne con una adición de $4 \%$ de melaza de 4,1. En la presente investigación la adición de $6 \%$ de melaza, favoreció la producción de ácido láctico, consecuentemente, a una disminución en el pH durante el proceso. Es importante enfatizar que a pesar del alto contenido de humedad $(84,17 \pm 0,23 \%)$ del maní forrajero, se alcanzaron valores adecuados de $\mathrm{pH}$, lo que indica que la adición de carbohidratos solubles está contrarrestando el efecto negativo de la humedad sobre el proceso fermentativo ocurrido en el silo (Henderson 1993).

Con relación a la capacidad de amortiguamiento del material, en el Cuadro 1 se observan dos etapas durante el proceso fermentativo: la primera, va desde los 10 a los 30 días del proceso con una capacidad promedio de $104,58 \pm 3,10$ meq de $\mathrm{NaOH}$ por cada $100 \mathrm{~g}$ de material y de $92,79 \pm 1,87$ meq de $\mathrm{NaOH}$ por cada $100 \mathrm{~g}$ de material para la segunda etapa, que va desde los 30 a 40 días hasta el final del proceso. Los datos encontrados en esta investigación son menores a los encontrados por McDonald (1981) para lucerne, de 253,0 meq Na0H/100g MS y por Playne y McDonald (1966) para trébol rojo de 142,1 a 147,1 meq $\mathrm{Na0H} / 100 \mathrm{~g}$ MS. Aunque en este trabajo se utilizó la metodología descrita por Playne y McDonald (1966), la diferencia podría radicar en el concepto de maceración (licuado), en esta investigación lo que se hizo fue golpear el material varias veces hasta romper los tallos y las hojas presentes.

El material ensilado presentó un valor promedio de 98,68 meq $\mathrm{NaOH} / 100 \mathrm{~g} \mathrm{MS}$, similar al obtenido para leguminosas por Playne and McDonald (1966), quienes asocian este valor con el incremento en la formación de lactatos y acetatos durante la fermentación. Según los mismos autores, la capacidad amortiguadora con respecto al material inicial se incrementa rápidamente, y se duplica en los tres días del proceso fermentativo. En la presente investigación, al haberse favorecido la producción de ácido láctico mediante la adición de melaza, se causó un aumento en la capacidad amortiguadora del material ensilado, principalmente en los primeros estadios del proceso. En el Cuadro 1 se describe la ecuación que permite estimar el comportamiento de la capacidad de amortiguamiento durante el proceso.

\section{Ácidos grasos volátiles}

El Cuadro 1 describe el comportamiento de los dos principales ácidos grasos volátiles: láctico y acético. A los 10 días de iniciado el proceso, se logra alcanzar la mayor concentración de ácido láctico y acético, las cuales promediaron 3,67 $\pm 0,02 \%$ MS y 1,16 $\pm 0,03$ $\% \mathrm{MS}$, respectivamente. Este resultado concuerda con lo informado por Moore y Peterson (1995), donde la concentración máxima de ácido láctico se alcanzó entre los tres y nueve días de iniciado el proceso. Lo que se asocia con la reducción del pH, la disminución de la proteólisis (McKersie 1985) y la reducción del crecimiento de microorganismos indeseables como las levaduras, enterobacterias y clostridias en el ensilado (McDonald et al. 1991). Con respecto al ácido butírico, sólo se cuantificó en los muestreos de 10 y 20 días post iniciado el proceso fermentativo, las concentraciones promedio en tales muestreos fueron de 0,06 y 0,02 $\%$ en base seca, respectivamente, lo cual se relaciona al nivel de melaza aplicado (6\% en base fresca), que favoreció un proceso adecuado de conservación. 
En la presente investigación durante el proceso fermentativo, probablemente prevaleció un proceso heterofermentativo, que dependiendo del tipo de carbohidrato que origina la reacción, podría representarse de la siguiente manera (Tobía 2004):

a. 1 pentosa => 1 ácido láctico +1 ácido acético o 1 etanol

b. hexosa => 1 ácido láctico $+1 \mathrm{CO}_{2}+1$ ácido láctico o 1 etanol

Tal comportamiento se debe al tipo de silo que se utilizó (bolsa sellada al vacío) y al nivel de melaza empleado (6\%), lo cual provocó un ambiente anaeróbico inmediato, donde ni el contenido de proteína, ni la alta capacidad buffer del maní forrajero, lograron evitar la disminución del pH a 3,7. McDonald y Henderson (1962) para la leguminosa Trifolium sp, concluyeron que se requiere, como mínimo $6 \%$ de ácido láctico para reducir el $\mathrm{pH}$ a 4,0, probablemente debido al nivel de melaza aplicado al material.

Los valores de ácido láctico y acético son menores que los obtenidos por Tobía (2004) para soya con $6 \%$ de melaza, los rangos informados fueron de $5,70 \%$ a 6,55 $\%$ MS y de $1,22 \%$ a $1,40 \%$ MS, respectivamente.

\section{CONCLUSIONES}

El ensilado de maní forrajero con la adición de 6 $\%$ melaza en base fresca tiende a estabilizarse a partir de los 10 días de almacenamiento anaerobio, lo cual permite hacer uso de este material en la suplementación animal, a partir de este momento.

Durante el proceso fermentativo ocurre una disminución en el contenido de la materia seca; de la fibra y de la proteína, en esta última, asociado con un aumento en la concentración de $\mathrm{N}$-amoniacal. Los valores de acidez y de $\mathrm{N}$-amoniacal cuantificados en la presente investigación permiten clasificar de grado aceptable el ensilado de maní forrajero.

En las fracciones de la proteína ocurren alteraciones durante el proceso fermentativo, con aumentos en la fracción insoluble aprovechable del material. Lo que potencia su uso en animales de alto potencial genético (leche o carne), debido a su aporte de proteína que logra sobrepasar el rumen.

Ensilar materiales de leguminosas perennes, como el maní forrajero, es una alternativa a considerar para la reducción de los costos de alimentación, ya sea mediante la sustitución de granos importados o para mantener la productividad en periodos de merma del componente forrajero en sistemas de producción de rumiantes.

\section{LITERATURA CITADA}

ARGEL, P.; VILLAREAL, M. 1998. Nuevo maní forrajero perenne (Arachis pintoi Krapovickis y Gregori). Cultivar Porvenir (CIAT 18744). Leguminosa herbácea para la alimentación animal, el mejoramiento y conservación del suelo y el embellecimiento del paisaje. Ministerio de Agricultura y Ganadería de Costa Rica (MAG). Centro Internacional de Agricultura Tropical. Boletín Técnico. 32 p.

ALZUETA, C.; CABALlERO, R.; REVOLE, A.; TREVINO, J.; GILL, A. 2001. Crude protein fractions in common vetch (Vicia sativa L.) fresh forage during pod filling. J. Anim. Sci. 79: 2449-2455.

AGUILERA, G. 1975. Dynamics of the fermentation of tropical grass silage 1. Elephant grass (P. purpureum) without additives. Cuban J. Agric Sci. 9: 227-235.

AOAC (ASSOCIATION OFFICIAL OF ANALYTICAL CHEMIST). 1990. Official methods of analysis. 15 ed. AOAC Arlinton V.A.

BROWN, W.; PITMAN, W. 1991. Concentration and degradation of nitrogen and fiber fractions in selected tropical grasses and legumes. Tropical Grasslands 25:305-312.

CHALUPA, W.; SNIFFEN, C. 1996. Protein an aminoacid nutrition of lactating dairy cattle today and tomorrow. Animal Feed Science and Technology. 58: 65-75.

DORMOND, H.; ROJAS, A.; JIMÉNEZ, C.; QUIROS, G. 2000. Efectos de niveles crecientes de seudotallo de 
guineo en combinación con ensilajes de maíz, sobre el crecimiento de terneras Jersey, durante la época seca. Agronomía Costarricense 24 (2): 31-40.

ELIZALDE, J.; MERCHEN, N.; FAULKNER, D. 1999. Fractionation of fiber and crude protein in fresh forages during the spring growth. J. Anim. Sci. 77: 476-484.

GIVENS, D.; RULQUIN, H. 2004. Utilization by ruminants of nitrogen compounds in silages-based diets. Review. Animal Feed Science and Technology 114:1-18.

HENDERSON, N. 1993. Silage additives. Animal feed science and technology 45:35-56.

HRISTOV, A.; SANDEV, S. 1998. Proteolysis and rumen degradability of protein in alfalfa preserved as silage, wilted silage or hay. Animal Feed Science and Technology 72:175-181.

LICITRA, G.; HERNÁNDEZ, T.; VAN SOEST, P. 1996. Standardization of procedures for nitrogen fractionation of rumiant feeds. Animal Feed Science and Technology 57: 347-358.

MAHANNA, B. 1997. Troubleshooting silage problems with "Seed to Feed" considerations in silage: Field to Feedbunk. Proceedings of the silage: Field to Feedbunk. North American Conference: 346-382:NRAES Publication 99. Cooperative Extension, Ithaca, NY.

McDONALD, P. 1981. The biochemistry of silage. Wiley. $226 \mathrm{p}$.

McDONALD, P.; HENDERSON, A. 1962. Buffering capacities of herbage samples as factor of silage. Journal of Science and Food Agriculture (13): 395-400.

McDONALD, P.; HENDERSON, A.; HERON, S. 1991. The Biochemistry of silage. 2 ed. Chalcombe Publ., Bucks, England.

McKERSIE, B. 1985. Effect of $\mathrm{pH}$ on proteolysis in ensiled legume forage. Agronomy Journal 77:81-86.

MOORE, K.; PETERSON, M. 1992. Post-harvest physiology and preservation of forages: Proceeding of a Symposium sponsored by C-6 of the Crop Science Society of America. Annual Meetings CSSA: 1-6 Nov. Minneapolis, USA. Serie CSSA Special Publication 22. 115 p.

MORENO, A. 1977. Evaluación de ensilajes de pasto Panamá (Saccharum sinense), para la alimentación de vacas de doble propósito. Tesis Magíster Scientiae. Turrialba, Costa Rica. Universidad de Costa Rica. Centro Agronómico Tropical de Investigación y Enseñanza. 98 p.

MORRISON, I. 1979. Changes in the cell wall components of laboratory silages and the effect of various additives on these changes. J. Agric. Sci. Camb. 93: 581-586.

PEZO, D. 1981. Ensilajes de forrajes tropicales. En producción y utilización de forrajes en el trópico. Turrialba, Costa Rica. CATIE. 141 p.

PLAYNE, M.; McDONALD, P. 1966. The buffering constituents of herbage and silage. J Sci. Food Agric. 17:264-268.

ROJAS, A. 1985. Effect of rolled corn silage on digestion of nutrients and feedlots performance of growing steers. Tesis de Maestría. Universidad del Estado de Iowa. Iowa, Estados Unidos. 93 p.

ROJAS, A. 1999. Producción, Costo y Utilización de Ensilajes en el Ganado Lechero. Seminario: Alimentación de la vaca lechera en el verano. Costa Rica. Universidad de Costa Rica-Elanco-Dos Pinos. 7 p.

SAS. 1985. User guide: Statistic. SAS. Inst. Inc. Cary. NC. USA.

SINGH, K.; HONIG, H.; WERMKE, M.; ZIMMER E. 1996. Fermentation pattern and changes in cell wall constituents of straw-forage silages, straws and partners during storage. Animal Feed Science and Technology 61:137-153.

TOBIA C. 2004. Introducción del ensilaje de soya en un sistema de producción de leche en el trópico húmedo de Costa Rica. Tesis sometida al Programa de Doctorado en Sistemas de Producción Agrícola Tropical Sostenible para optar al grado de Philophiae Doctor, Universidad de Costa Rica. Costa Rica. 120 p. 
VAN SOEST, P. 1994. Nutritional ecology of the ruminants 2 ed. Comstock Publishing, Cornell University Press, Ithaca, NY. 374 p.

VAN SOETS, P.; ROBERTSON, J. 1985. Analysis of forages and fibrous food: A laboratory manual for animal science. New York. Cornell University. 613 p.

VILLARREAL M., COCHRAN R., VILLALOBOS L; ROJAS-BOURRILLÓN A.; RODRÍGUEZ R.;
WICKERSHAM T. 2005. Dry-matter yields and crude protein and rumen degradable protein concentrations of three Arachis pintoi ecotypes at different stages of regrowth in the humid tropics. Grass and Forage Science 60: 237-243.

WINGCHING-JONES R, ROJAS-BOURRILLON A. 2005. Composición nutricional y parámetros fermentativos del ensilaje de maní forrajero (CIAT 18734 y CIAT 18344). Agronomía Costarricense 30 (1): 87-100. 